\title{
You can publish an editorial
}

$\mathrm{I}$

seldom read editorials in medical journals, especially the ones from "Mount Olympus". I do read the light breezy ones with an original or irreverent point of view. The late Robert Goldwyn was a master at making a point with humour. We miss him.

Editorial writing is a good way to express what you think. Here are a few suggestions for writing your own editorials.

The first job of the writer is to be read. Be bold and catch the reader's attention. Think of your favourite writers and emulate them. Ask yourself, "How does PJ O'Rourke, Joel Stein or Malcolm Gladwell do it?"

Start with a burning idea and write it in 800 words. This fits nicely on one page. Have a beginning, a middle and an end. Think of an opening line and the ending first. Make the reader want to read the whole article and want more. Make your point once.

Use humour if you can. This is important to being read, but can be difficult to write. Be lighthearted, but never use sarcasm, which is too powerful. Use irony if you can, but use it gently. How did Stephen Leacock and Mark Twain do it? They told stories and liked the people they wrote about. Making fun of yourself works. Do not pontificate.

Spend a lot of time choosing your subject. Sit down and write quickly.

There will be problems, but when you rewrite, it will be a lot better. Do not spend a lot of time on grammar; just write clearly, and never use a big word when a little word will do. Eliminate 'than's, and's and then's' following The Elements of Style by William Strunk Jr and EB White.

The journal editor's job is to be objective. An editor can comment on wording to make your ideas clearer, but it is your job to submit it in finished form. Do not expect the editor to rewrite opaque writing.

If you have a particular grievance or a physician's hobby-horse you like to ride, an editorial is a great way to express yourself. It helps you hone your point of view as you learn the weakness of your argument by writing it.

You need to choose a style and a voice. It can be a debate, with you taking both sides. It can be a story with a meaning. It can be a personal experience. Whatever it is, it is a style you have chosen for that editorial. If it works, use it. If it doesn't, start again.

A personal question about scientific papers. Why can't they be briefer and more entertaining? How did physicians learn to write obscurely? It is time to forget jargon and write simply. Just state the problem you

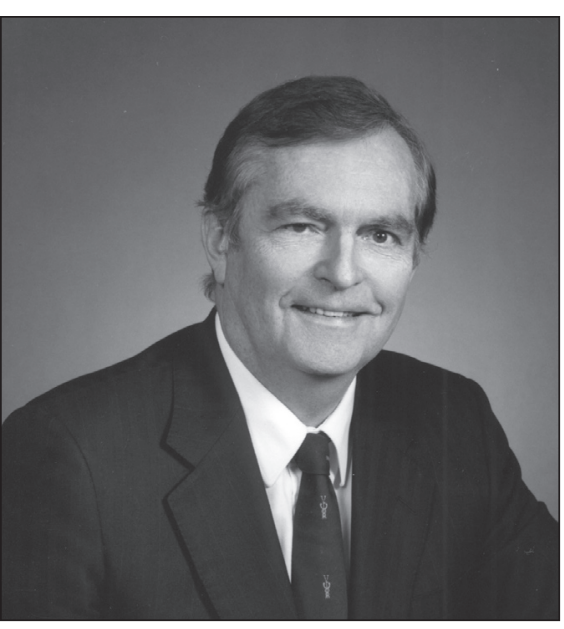
wanted to solve and how you solved it. Show, don't tell. Tell if you must, but clearly. If we used metaphor and visual imagery in journal articles, we might read more of them.

A novelist completed his masterpiece, a 400-page tome and asked a reader how he liked it. The reader considered what he really thought, and said, 'next time, write shorter'. Be surgical and debride it! Love words and play with them.

Remove the debris and leave the gold.

Discussing a problem is fine, but it is better to propose a solution.

Entertain, be short and use imagery.

Get in, make a point and get out.

Bring the fog into focus.

John R Taylor 